\title{
Pasca-Islamisme dalam PAS: Analisis Terhadap Kesan Tahalluf Siyasi
}

\author{
Post-Islamism in PAS: An Analysis on the Impact of Tahalluf Siyasi
}

MUHAMMAD FAIZ MUKMIN ABDUL MUTALIB* \& WAN FARIZA ALYATI WAN ZAKARIA ${ }^{1}$

\begin{abstract}
This study discusses the impact of post-Islamism in the Parti Islam Se-Malaysia (PAS), specifically on tahalluf siyasi (political alliance) with Pakatan Rakyat (People Coalition). Post Islamism is a contemporary Islamist school of thought with regard to politics. The characteristics of post-Islamism such as toleration, participation and inclusivism has greatly influenced the modus operandi of the Islamic movement including PAS. Inclusiveness in post-Islamism had motivated PAS in having political coalition with more liberal parties such as Parti Keadilan Rakyat (PKR) and Democratic Action Party (DAP). Post-Islamism as popularised by Asef Bayat was established on Western knowledge narratives, therefore such study as this should be done in order to recognise its negative impacts. To achieve this objective, the researchers used qualitative method through the process of collecting by scrutinising and analysing related data on the discourse of post-Islamism. The result of the study shows that PAS has been affected by the post-Islamism. The impact of post-Islamism in PAS however shows that PAS did not play dominant role in the Coalition throughout the political alliance. Besides, PAS also compromised a lot with its principles including its Islamic principles. Post-Islamism had also affected PAS in reducing the Muslims vote to PAS because of their support for DAP. This study therefore exposed the negative sides of post-Islamism to Islamic movement. With current development in PAS, it is hoped that this exposure will consult the Islamic movements in critically weighing their support to any kind of ideas particularly from the West.
\end{abstract}

Keywords: Malaysian politics, PAS, post-Islamism, political coalition

Sebagai parti yang berideologi Islam, PAS dibezakan dengan parti-parti lain di Malaysia ini atas asas ideologi. Islam adalah matlamat akhir perjuangan mereka. Menurut Kamarudin Salleh (2010), mana-mana tindakan dijustifikasikan oleh doktrin Islam dan juga respons terhadap terhadap perubahan politik mestilah dikaji-lihat dari sudut pandang politik Islam. Penerimaan atau bangkangan menyentuh tawar-menawar politik hendaklah berdasarkan pertimbangan sama ada selaras dengan prinsip-prinsip dan doktrin Islam serta mempunyai keuntungan politik kepada Islam.

Berdasarkan beberapa definisi pengkaji gerakan Islam seperti Asef Bayat (2013), Ihsan Dagi (2013) dan Noah Feldman (2013), PAS jelas terkesan dengan pasca-Islamisme. PascaIslamise yang mengandungi unsur positif seperti penekanan kepada Good Governance, ekonomi,

\footnotetext{
1 Muhammad Faiz Mukmin Abdul Mutalib*(Corresponding author), Masters candidate at Dept. of Theology and Philosophy, Universiti Kebangsaan Malaysia, 43600, BANGI, Malaysia, email: ibnuhajar_asqalani@yahoo.com; Wan Fariza Alyati Wan Zakaria, Ph.D., Senior Lecturer at Dept. of Theology and Philosophy, Universiti Kebangsaan Malaysia, 43600, BANGI, Malaysia, email: aufaa@ukm.edu.my.
} 
keadilan sosial dan keperluan rakyat, juga mengandungi unsur negatif seperti fahaman hak asasi manusia, kebebasan individu, liberalisme dan pluralisme agama. Memandangkan PAS terkesan dengan pasca-Islamisme maka artikel terdorong untuk meneliti sejauh mana pascaIslamisme ini di dalam PAS khususnya kesan ketika mereka bertahalluf siyasi (persepakatan politik) di dalam Pakatan Rakyat.

Kajian ini timbul memandangkan di luar negara seperti Iran, pasca-Islamisme telah melahirkan masyarakat yang mengamalkan cara hidup Barat. Segala unsur-unsur Barat dibawa masuk dan diamalkan masyarakatnya. Hal ini berdasarkan kenyataan Asef Bayat (2013) di dalam artikel The Making of Post-Islamist Iran, beliau menyebut:

In 1989, the pragmatist President Rafsanjani appointed Gholamhussein Karbaschi, an ex-theology student turned urban planner, to fix the capital city. In the course of eight years (1990-1998), Tehran assumed a new character that had little to do with the image of an Islamic city. Its new aesthetic, spatial configuration, symbolism, freeways, huge commercial billboards, and shopping malls emulated Madrid or even Los Angeles more than they did Karbala or Com. While forced use of head scarves and gander segregation were still enforced by the state, the municipality's newly constructed six hundred public parks brought men and women, boys and girl, together in public places. Recreational activities, including mountain climbing, skiing in north Tehran, and bike riding in the forest plantations on the city outskirts, facilitated a less restricted mingling of the sexes.

\section{Konsep Pasca-Islamisme}

Dalam memahami pasca-Islamisme, definisi konsep hendaklah diteliti dengan baik. Kajian ini meneliti definisi konsep pasca-Islamisme yang berkait dengan tahalluf siyasi. Bagi Ihsan Dagi (2013), pasca-Islamisme adalah: "embrace participation, inclusion, tolerance, emancipation, and human rights and liberties blended with Islamic morality, brotherhood, and solidarity in order to compensate for the loss of divine in shaping the model of governence". Pasca-Islamisme dimaksudkan dengan bersifat terbuka (inklusif), toleransi dan partisipasi dalam masyarakat sivil.

Sementara itu Noah Feldman (2013) pula mentafsirkan pasca-Islamisme sebagai bahasa berbeza dengan sebelumnya (Islamisme) yang digunakan Islamis dalam menanggapi sesuatu isu. Dalam hal ini, beliau membuat perbandingan di antara Parti Ennahda di Tunisia dan Ikhwan di Mesir. Kata Feldman: "The contrasting personalities and styles of their leaders, however, have pushed Ennahda and the Brotherhood to behave differently when negotiating religion with secularaists in their respective countries". Perbezaan menanggapi suatu perkara meletakkan pasca-Islamisme berbeza dengan pemikiran Islamisme, sepertimana PAS yang kini menanggapi kelompok bukan Islam dangan tanggapan berbeza.

Asef Bayat (2013) pula menyebut: "I saw post-Islamism not only as a condition but also as a project, a conscious attempt to conceptualize and strategize the rationale and modalities of transcending Islamism in social, political, and intellectual domains". Pasca-Islamisme sebagai bentuk strategi Islamis meneruskan survival perjuangan Islam. Dalam konteks PAS, bersifat terbuka dengan mengadakan tahalluf siyasi adalah satu bentuk strategi meneruskan perjuangan mereka di dalam suasana masyarakat berbilang kaum di Malaysia.

Pasca-Islamisme dilihat bersifat positif kerana mampu meneruskan perjuangan gerakan Islam dalam konteks dunia moden. Keterbukaan gerakan Islam membolehkan penerimaan ramai masyarakat pelbagai fahaman dan agama untuk turut sama-sama menyokong dan 
Vol. 8: (Dec.) 2015

bekerjasama bersama mereka khususnya ketika pilihanraya. Namun keterbukaan ini perlu dinilai dan diteliti agar gerakan Islam tidak lari dari perjuangan asal mereka mendaulatkan Islam, agar tiada gerakan Islam bersikap optimis mengejar kemenangan tetapi dalam masa yang sama terpaksa menggadaikan prinsip kerana ingin menjaga sokongan dan kerjasama yang diperolehi.

\section{Tahalluf Siyasi dan Pasca-Islamisme}

Tahalluf siyasi secara umumnya boleh disama ertikan kepada beberapa makna seperti diplomasi politik, kompromi politik, kerjasama politik, koalisi politik, pakatan politik dan integrasi politik. Sebuah artikel dari laman sesawang National Democratic Institute mentakrifkan tahalluf siyasi seperti berikut (Audi t.th.):

$$
\begin{aligned}
& \text { إن التحالف بشكل عام يعني اتحادا مؤقتا بين مجموعتين أو أكثر وخاصة الأحزاب } \\
& \text { السياسية من أجلالحصول على تأثير أعظم أو نفوذا أكبر من الجماعات والأحزاب المنفردة } \\
& \text { عندما تريد تحقيق أهدافها .و بالتركيز على الغايات والأمداف المشترآة يستطيع جميع } \\
& \text { الأعضاء بناء قوتهم والحصول على الفائدة من القضايا ذات الإهتمام المشترك ـ ـ وبوجود } \\
& \text { أهداف معينة مثل الفوز بالانتخابات أو تمرير قانون ما أو تشكيل تحالفا حكوميا فإن عمر } \\
& \text { هذا التحالف ينتهي مع تحقيق تلك الغايات. و يجب على جميع أعضاء التحالف إن يشعروا } \\
& \text { بأنهم يربحون أو يحصلون على شيء ما من خلال تحالفهم هذا وهي حالة فوز الجميع. }
\end{aligned}
$$

Maksudnya: Gabungan itu secara amnya bermakna kesatuan sementara di antara dua atau lebih khususnya parti-parti politik bagi mendapat kesan atau kejayaan yang lebih besar berbanding bersendirian bagi mencapai matlamat mereka, iaitu dengan menumpukan kepada matlamat yang sama, objektif yang sama, dan membina kekuatan dengan isu-isu yang mempunyai kepentingan bersama. Seperti memenangi pilihanraya atau meluluskan undang-undang atau pembentukan sebuah kerajaan campuran, jangka hayat perikatan ini berakhir dengan tercapainya matlamat ini. Mestilah semua ahli pakatan itu, merasakan mereka menang atau semuanya dalam kondisi menang-menang sepanjang pakatan tersebut berlangsung.

Takrifan ini memberi gambaran kepada kita bahawa tahalluf siyasi adalah sebuah strategi politik dengan cara bekerjasama dan bertujuan mencapai matlamat ataupun objektif yang sama dengan kumpulan-kumpulan lain. Sebuah kesepakatan yang mempunyai tempoh tertentu dan tidak berkekalan selama-lamanya. Berdasarkan sejarah Islam, Rasulullah (s.a.w.) pernah mengadakan persepakatan politik dengan golongan bukan Islam. Di antaranya ialah, peristiwa Perjanjian Hudaibiyyah. Peristiwa penting ini berlaku pada tahun keenam Hijrah di antara Kerajaan Islam Madinah dengan orang Quraisy Mekah. Di antara isi penting perjanjian itu adalah (Shukeri Muhammad 2009):

- Tiada peperangan antara orang Quraisy dan orang Islam Madinah selama 10 tahun. 
- Orang Islam tidak boleh masuk Mekah pada tahun itu.

- Orang Islam boleh memasuki Mekah pada tahun hadapan untuk urusan ibadat.

- Ketika memasuki Mekah, orang Islam tidak boleh mengeluarkan pedang daripada sarungnya selama berada di Mekah.

- Mereka dibenarkan berada di Mekah selama tiga hari saja, dan mesti keluar selepas tempoh itu.

- Nabi Muhammad mesti menghantar balik mana-mana orang Quraisy yang datang berlindung di Madinah.

- Orang Quraisy tidak perlu menghantar pulang mana-mana orang Islam yang datang berlindung di Madinah.

Peristiwa yang dicatatkan ini membuktikan bahawa, tahalluf siyasi memang pernah dilaksanakan di dalam Islam. Ia dibuktikan dengan pengamalan Rasulullah (s.a.w.) sendiri. Sesetengah keadaan ia menjadi keperluan. Secara tidak langsung hukum tahalluf siyasi adalah harus memandangkan sunnah yang dibuat Rasulullah (s.a.w.) Yusuf al-Qaradawi apabila ditanya tentang hukum bergabung di dalam pemerintahan bukan Islam. Secara tidak langsung ia berkaitan tentang kerjasama orang Islam dengan orang bukan Islam dalam hal pentabiran, semestinya hal politik. Beliau memberi jawapan (Yusuf al-Qaradawi 2002):

Tidak ada larangan untuk bergabung dengan pemerintahan bukan Islam yang sanggup menjalankan syariat Islam dan dibolehkan bersama orang bukan Islam atau sesiapa sahaja yang sanggup meminimumkan kezaliman, keburukan dan kejahatan dengan apa cara sekalipun, maka dia mesti melakukannya. Dia mesti menolong orang yang tertindas, membantu orang yang dizalimi, menguatkan orang yang lemah dan menyempitkan ruang dosa dan kejahatan.

Sifat inklusif atau terbuka yang ada pada tahalluf siyasi ini bersesuaian dengan definisi pasca-Islamisme tadi. Selain inklusif ia jelas sebuah ijtihad dalam lapangan politik. Di Malaysia, hal ini diamalkan PAS bagi meraih sokongan massa kepada mereka. Pada tahun 1990-an sahaja, PAS sudah mengadakan pakatan politik ataupun istilahnya 'tahaluf siyasi' sebanyak tiga kali iaitu bersama Angkatan Perpaduan Ummah (APU), Gerakan Keadilan Rakyat Malaysia (GERAK) dan Barisal Alternatif (BA). Sebelum tahun 90-an, PAS pernah bersama dengan Perikatan yang kemudiannya menukar nama kepada Barisan Nasional. Ini menunjukkan PAS tidak asing dengan tahaluf siyasi. Pada masa kini, PAS sedang melangsungkan tahaluf siyasinya di dalam Pakatan Rakyat yang dianggotai oleh PAS, PKR dan DAP. Pakatan Rakyat diwujudkan menggantikan Barisan Alternatif sejak tahun 2008 dan terus kekal sehingga kini.

Transisi sifat PAS dari eksklusifisme kepada inklusifisme ini bermula dengan kemasukan golongan profesional ke dalam parti itu. Menurut Mohd Izani, usaha untuk mengubah pendekatan PAS mula kelihatan apabila timbulnya usaha untuk 'mengintelekkan ulama dan mengulamakan intelek'. Angin perubahan ini dikatakan telah meresap ke dalam PAS selepas parti itu mengadakan Muktamar Tahunan ke-41 pada 1995. Keadaan ini juga memperlihatkan kemasukan golongan profesional sebagai langkah 'untuk mengubah corak perjuangan PAS yang kini sudah nyata dan jelas bukan sahaja tidak releven dengan arus pembangunan masa kini tetapi lebih daripada itu tidak dapat diterima oleh rakyat' (Mohd Izani Mohd Zain 2007). Kemasukan golongan profesional bukan sahaja ingin memaparkan keterbukaan PAS bahkan mengharapkan akan ada sebuah perubahan yang positif bagi memastikan kejayaan PAS meraih lebih banyak kemenangan di dalam pilihanraya. Kemasukan 
tenaga koprat, ahli akademik dan golongan profesional berjaya menafikan persepsi yang mana PAS adalah parti untuk 'pak lebai' dan 'orang kampung'.

Perubahan pendekatan PAS jelas terzahir apabila buat julung-julung kalinya bekerjasama dengan Democratic Action Party (DAP) melalui pakatan Barisan Alternatif (BA) dalam usaha berhadapan Barisan Nasional (BN) untuk pilihan raya umum 1999. Dalam hal ini PAS bersetuju untuk menggugurkan slogan penubuhan negara Islam dalam menifestonya, sebaliknya mengutamakan hal-hal yang boleh disepakati bersama secara konsensus seperti demokrasi, keadilan, dan pemerintahan yang baik. Keterbukaan PAS kali ini termasuk membuka keahlian ahli bukan Islam telah menggambarkan parti itu bersedia untuk berkompromi dengan DAP. Dengan perubahan seperti ini, boleh disimpulkan PAS tidak mempunyai aliran pemikiran yang tetap. Sejak dari penubuhan mereka pada 1951, PAS sudah mengalami beberapa perubahan pemikiran yang mana pada awal dahulu mereka lebih bercorak nasionalisme kemudian fundamentalisme, dan kini liberalisme. Perubahan mereka bergantung kepada suasana dan keadaan. Jika keadaan dan suasana berubah mereka turut juga berubah.

Keterbukaan PAS sehingga ke tahap ini memberi nilaian bahawa PAS hampir sepenuhnya berubah daripada politik era 70 -an dan 80 -an kepada wacana politik baru yang bersifat liberal. Jika sebelumnya mereka lebih eksklusif namun kini mereka inklusif menerima siapa sahaja sesuai dengan slogan PAS for All dan ia dibuktikan dengan kewujudan DHPP. Namun, keterbukaan dan pendekatan-pendekatan yang agak berbeza sebelumnya ini sudah pasti memberi kesan-kesan tertentu kepada PAS.

\section{Kesan Pasca-Islamisme: Analisa Tahalluf Siyasi di dalam Pas}

Dengan sifat pasca-Islamisme (inklusivisme) yang diamalkan PAS, kini mereka di dalam Pakatan Rakyat mengadakan tahalluf siyasi bersama PKR dan DAP. Beberapa kesan dapat dilihat hasil tahalluf siyasi kali ini:

- PAS sangat terpinggir di dalam PR. Rakan-rakan pakatan yang lain lebih menonjol kerana lontaran idea dan kemenangan besar yang diperolehi mereka. Isu ketandusan idea membuatkan pimpinan PAS kurang menonjol. Ini menimbulkan persepsi kalangan masyarakat bahawa PAS bukan saingan kepada rakan-rakan dalam Pakatan Rakyat. Keadaan ini dibuktikan dengan dakwaan Ketua Penerangan PAS Perak, Mohd Misbahul Munir Dasuki, menurut beliau: “. . kadang-kadang kita takut untuk memberi padangan terhadap sesuatu isu kerana tidak ada keupayaan berhujah" (Mohd Misbahul Munir 2014). Kerana itulah parti-parti lain dalam Pakatan Rakyat lebih mendominasi.

- Kedudukan PAS yang tidak dominasi ini pasti memberi kesan kepada persepsi orang Melayu-Islam di Malaysia. Orang Melayu sebagai teras kepada kemenangan dua parti utama Melayu iaitu UMNO dan PAS, sudah pasti akan membuat perbandingan di antara dua parti tersebut. Antara perbandingan yang boleh difikirkan, jika PAS bersama PR, orang Melayu tidak akan terbela kerana PAS hanyalah suara pinggiran. PKR pula dilihat tidak mewakili orang Melayu. Jika mereka hendak memilih UMNO, parti ini ada masalah integriti namun, dominasi mereka di dalam BN akan membuatkan orang Melayu yakin bahawa UMNO mampu mempertahankan hak orang mereka. Akhirnya orang Melayu tetap memilih UMNO.

- Oleh kerana PAS yang paling lemah dalam PR, PAS seperti terpaksa berkompromi dengan banyak isu sehinggakan isu yang berkait prinsip di dalam Islam. Hal ini terbukti dalam isu rampasan Bible, kalimah 'Allah' dan isu murtad di Selangor. Sebagai contoh isu kalimah 'Allah', PAS melalui Mursyidul Am mereka berpendirian orang bukan Islam 
boleh menggunakan kalimah 'Allah' sebagaimana diputuskan oleh Majlis Syura Ulama mereka (PAS Pusat 2013). Walaupun dari sudut perbincangan ilmiah, PAS boleh dikatakan betul dengan pendirian mereka itu namun, harus diingat, sebagai sebuah parti politik, PAS perlu bijak menilai persepsi orang Melayu-Islam dalam isu kalimah 'Allah' ini. Bagi orang Melayu, kalimah 'Allah' adalah kepunyaan mereka. Apabila PAS berpendirian seperti mana tuntutan orang bukan Islam maka orang Melayu berpersepsi yang PAS sudah tunduk kepada tuntutan orang bukan Islam.

- PAS juga terpaksa menggadaikan prinsip perjuangan mereka demi menjaga hubungan tahalluf siyasi bersama rakan-rakan pakatan yang lain. Jika dinilai amanat Abdul Hadi Awang 1981, beliau mengatakan: "kita menentang Barisan Nasional bukan kerana dia lama memerintah kerajaan. Kita menentang dia ialah kerana dia mengekalkan perlembagaan penjajah, undang-undang kafir, mengekalkan peraturan jahiliyah" (Asri Zainul Abidin 2013). Beliau menentang BN kerana ideologi sekular yang dianggap peraturan jahiliyah, namun kini, PAS pula bersama DAP yang juga berideologi sekular.

- PAS juga sudah bersetuju dengan Ketuanan rakyat apabila turut sama bersetuju dengan Buku Jingga (Pakatan Rakyat 2013). Ketuanan Rakyat adalah asas politik demokrasi. Di dalam politik demokrasi, nilai-nilai seperti kebebasan (liberty), kesamarataan (equality) dan hak asasi manusia (human rights) merupakan perjuangan utama mereka. Perjuangan ini nampaknya sudah bertapak di Malaysia, seperti kewujudan COMANGO dan LGBT. Ahli-ahli yang ada di dalam NGO-NGO ini merupakan orang kuat yang pro-PR. Ini menunjukkan kelompok ini melihat prospek untuk berkembang itu ada pada PR bukan BN kerana suara Islam di dalam PR tidak kuat berbanding di dalam BN. Jika PAS terus bersama PR, PAS seolah bersekongkol dengan kelompok seperti ini, dan imej PAS akan rosak.

- Selain itu, antara kesan tahalluf siyasi di dalam PR ini ialah nada berbeza pimpinan PAS terhadap isu-isu yang melibatkan perjuangan asal dan ideologi PAS, sepertimana respons Dzulkefly Ahmad, Pengarah Pusat Penyelidikan dan Pembangunan PAS tentang negara Islam dan demokrasi. Menurut beliau: "I'm an Islamist democrat. Like a social democrat in the DAP, who believes and advances social democracy in its political advocacy, I believe in advocating Islam as a social and political order within the ambit of parliamentary democracy, besides being a religious conviction per se. In a multi-party a la-Westminster parliamentary democracy, all contending parties have their right to advocate, compete and seek for electoral mandate in an electoral process that should provide for a free and fair political contestation on a more or less level playing field. Viewed from this perspective, I must emphatically say that I'm least bothered wheter Malaysia should be or is a secular or an Islamic state. I'm least concerned as to whether you call this country secular or Islamic. What matters to me is the provision of equal opportunities" (Dzulkefly Ahmad 2012).

- Tahalluf siyasi juga mengubah sikap PAS yang asalnya tegas memperjuangkan Islam kepada sikap oportunis dengan politik demi menjayakan cita-cita Pakatan Rakyat menawan Putrajaya. Dengan sikap ini, PAS seperti sanggup melakukan apa sahaja demi mencapai kemenangan. PAS melalui Pengerusi Lajnah Perpaduan Nasional, Mujahid Yusuf Rawa menyatakan keperluan PAS kepada sebuah parti yang bersifat multiracial (Mujahid Yusuf Rawa 2009). PAS harus meneliti dengan baik terma multiracial ini, kerana dilihat multiracial dalam amalan Barat sebenarnya ke arah kesamarataan di antara kaum. Multiracial juga adalah gerakan pasca-modenisme yang menuntut hak dan tiada lagi penjajahan terhadap berbagai-bagai kumpulan agama, ideologi, ras, jantina, suku bangsa, dan pengelompokan masyarakat (Bustanuddin Agus 2013). Dalam konteks 
di Malaysia multiracial amalan Barat sama sekali tidak sesuai. Hal ini jika diizinkan akan membuka ruang kepada ideologi-ideologi yang bertentangan dengan Islam mentadbir dan memerintah negara.

- Jika PAS terus ingin bersifat multiracial, perkara yang perlu difikirkan ialah kesan terhadap ekonomi orang Melayu. Kelompok Melayu-Muslim di Malaysia adalah kelompok yang lemah dari sudut ekonomi. Umat Islam di Malaysia akan lebih tertindas dan ketinggalan jika dasar multiracial dengan pembahagian sama rata di antara kaum dilaksanakan kerana kelemahan-kelemahan yang ada pada orang Melayu seperti kurangnya pendedahan dan pengalaman menguruskan perniagaan dan sebagainya. Kelemahan orang Melayu dari sudut ekonomi terbukti sehingga kerajaan terpaksa mewujudkan Dasar Ekonomi Negara (DEB).

- PAS juga banyak mendapat tentangan khususnya dalam soal hudud. Isu hudud jelas terhalang selagimana PAS terus bersama PR kerana dua-dua rakan parti dalam PR menyatakan pendirian menolak pelaksanaan hudud. Tahalluf siyasi PAS bersama DAP dan PKR memperlihatkan masa depan suram dalam isu hudud. Berbeza jika PAS bersama UMNO apabila UMNO melalui Menteri di Jabatan Perdana Menteri Jamil Khir Baharom mempelawa kerajaan PAS Kelantan untuk bersama-sama berbincang tentang hudud. Sehingga kini Jawatankuasa Teknikal Peringkat Pusat yang diwujudkan bagi mengkaji pelaksanaan hudud atau Enakmen Kanun Jenayah Syariah II di Kelantan telah diwujudkan (Bernama 2014).

Tahalluf siyasi yang dijalankan PAS ini walaupun mendatangkan kebaikan seperti dapat meneruskan kelangsungan perjuangan gerakan Islam terutama bagi meraih sokongan masyarakat berbilang kaum di Malaysia tetapi dalam konteks agama Islam dan masa depan umat Islam, PAS harus menilai kembali tahalluf siyasi yang disertainya ini. PAS di dalam PR dilihat sebagai parti pinggiran dan tidak dominan. Keadaan ini menimbulkan persepsi buruk orang Melayu-Islam terhadap mereka. Persepsi ini boleh memberi kesan kepada sokongan yang akan diperolehi di dalam pilihanraya. Di dalam PRU 13 PAS sebagai parti tunjang Melayu Islam dalam PR mencatatkan kemerosotan kerusi Parlimen di kawasan majoriti Melayu iaitu sebanyak dua kerusi di Kelantan dan tujuh di Kedah (Mohd Hasbi Muda 2013). Jika persespi ini tidak diurus, PAS dijangka bakal mengalami kemerosotan undi Melayu.

Kemerosotan undi Melayu terhadap PAS akan lebih teruk jika PAS dilihat tidak mampu mempertahankan hak orang Melayu dan agama Islam. Sepertimana isu kalimah 'Allah', PAS berpihak kepada tuntutan orang bukan Islam. Keadaan ini memberi kelebihan kepada UMNO jika orang Melayu hilang kepercayaan mereka kepada PAS. Walaupun bersama PR, PAS tidak harus mengikut rentak rakan-rakan dalam PR tetapi harus ada pendirian teguh dalam soal agama Islam. Kesan yang lain, PAS jelas berubah sikap daripada memperjuangkan 'Negara Islam' kepada optimis memenangi pilihanraya. Sikap optimis seolah membuatkan PAS sanggup melakukan apa sahaja demi memenangi pilihanraya. Contoh yang disebut adalah PAS sebagai parti multiracial. Pelaksanaan PAS sebagai parti multiracial dibimbangi menghakis keistimewaan orang Melayu dan juga agama Islam. Berdasarkan kesan-kesan ini, kajian beranggapan ianya adalah hasil daripada sikap PAS yang menerima inklusifisme pascaIslamisme. Dalam era globalisasi masa kini tidak banyak gerakan Islam yang dapat menahan arus demokrasi yang sedang tersebar di seluruh dunia. Tanpa persediaan dan penelitian yang kemas berkaitan demokrasi sudah pasti akan membuatkan mereka terkesan dengan unsurunsur negatif di dalam pasca-Islamisme. 
Secara keseluruhannya PAS memang ada terkesan dengan pasca-Islamisme. Kajian terhadap kesan pasca-Islamisme di dalam PAS ini penting kerana posibiliti PAS membawa budaya dan arus baru dalam masyarakat adalah besar memandangkan pengaruh dan jumlah ahli yang besar. Selain itu, kajian ini juga penting bagi mendedahkan gerakan Islam tentang aspek negatif demokrasi agar lebih berhati-hati dan tidak bersikap asimilasi iaitu dengan hanya mencedok idea-idea Barat yang dirasakan sesuai dengan Islam tanpa dinilai terlebih dahulu. Sebagai gerakan Islam, PAS boleh mengambil langkah bijak dengan pendedahan seperti ini supaya tidak terjebak menjadi agen pembawa budaya yang melanggar syariat Islam. Justeru itu PAS dituntut supaya menilai kembali kedudukan mereka di dalam Pakatan Rakyat. Bukan sahaja aspek untung rugi dalam politik harus diambil kira bahkan yang lebih utama adalah masa depan agama Islam dan umat Islam di Malaysia. Sebagai gerakan Islam, PAS sebenarnya mampu mengorak langkah lebih jauh, bukan sekadar sibuk dengan kerja politik tetapi yang lebih utama adalah mendaulatkan agama dan memartabatkan bangsa. Kesibukan kerja politik, sifat oportunis politik, dan pemikiran politik kepartian membuatkan PAS terlepas pandang soal yang lebih utama dan luar dari kerangka politik iaitu pembangunan bangsa dan umat yang bermaruah. Penyertaan PAS dalam politik seharusnya menyelesaikan masalah umat yang sering ditohmah, dihina, dan dilabel mulai dari 'pribumi malas' sehinggalah 'Melayu mudah lupa' yang mana menggambarkan kelemahan umat Islam di Malaysia.

\section{References}

Asef Bayat. 2013. Post-Islamis at Large. In A. Bayat. Post-Islamism the Changing Faces of Political Islam, pp. 3-32. New York: Oxford University Press.

Asef Bayat. 2013. The Making of Post-Islamist Iran. In A. Bayat. Post-Islamism the Changing Faces of Political Islam, pp. 35-70. New York: Oxford University Press.

Asri Zainul Abidin. 2013. Home. Retrieved October 29 2014, from drmaza.com: http://drmaza.com/home/?p=2255.

Audi, C. B. n.d. Joining Forces. Retrieved March 23 2014, from https://www.ndi.org: https://www.ndi.org/files/joiningforces_arabic.pdf

Bernama. 2014. Berita. Retrieved October 2 2014, from www.malaysiakini.com: http://www.malaysiakini.com/news/268906.

Bustanuddin Agus. 2013. Islam dan Globalisasi. Johor Bharu: Jahabersa.

Dzulkefly Ahmad. 2012. Striving for Change. Kuala Lumpur: Buku Harakah.

Ihsan Dagi. 2013. Post-Islamism a la Turca. In A. Bayat. Post Islamism The Changing Faces of Political Islam, pp. 71-108. New York: Oxford University Press.

Kamarudin bin Salleh. 2010. Modenisme dalam Politik Islam : Sifat, Perkembangan dan Impaknya di Malaysia. Bangi: UKM.

Malaysianinsider. 2013. Bahasa. Retrieved August 31 2014, from www.themalaysianinsider.com: www.themalaysianinsider.com/bahasa/article/ngoislam-dedah-dalang-di-belakang-comango-antaranya-ambiga-dan-marina-mahathir.

Mohd Hasbi Muda. 2013. Kemenangan yang Tertangguh. Petaling Jaya: Megamind Leadership Counsaltancy.

Mohd Izani Mohd Zain. 2007. Islam dan Demokrasi. Kuala Lumpur: Penerbit University Malaya.

Mohd Misbahul Munir. 2014. Berita. Retrieved October 2 2014, from www.malaysiakini.com: http://www.malaysiakini.com/news/276331.

Mujahid Yusuf Rawa. 2009. Wajah Baru Politik Malaysia. Kuala Lumpur: Anbakri Publika.

Noah Feldman. 2013. BloombergView. Retrieved September 4 2014, from www.bloombergview.com: http://www.bloombergview.com/articles/2013-07-05/dont-blame-islam-for-the-failure-of-egypt-s-democracy. 
Oxford. 2014. Dictionaries. Retrieved October 3 2014, from www.oxforddictionaries.com: www.oxforddictionaries.com/definition/english/coalition.

Pakatan Rakyat. 2013. Buku Jingga. Retrieved September 25 2014, from demirakyat.my: http://demirakyat.my/en/gallery/buku-jingga-bahasa-malaysia-english.

PAS Pusat. (2013 1 March). Artikel. Retrieved October 2 2014, from www.pas.org.my: http://www.pas.org.my/v2/index.php/artikel/mursyidul-am/85-kenyataan-mursyidulam-2011-2013/1310-kalimah-allah-nik-aziz-ulangi-pendirian.

Shukeri Muhammad. 2009. Siyasah Syar’iyyah dalam Membentuk Gagasan Fiqh Masyarakat Majmuk. Simposium Fiqh Masyarakat Bukan Islam dalam Negara Islam, pp. 1-21. Shah Alam: Persatuan Ulama Malaysia Cawagan Selangor.

Yusuf al-Qaradhawi. 2002. Fiqh Daulah Menurut Perspektif Islam. Bangi: Maktabah alQaradhawi. 